\title{
Autoantibodies in Spondyloarthritis, Focusing on Anti-CD74 Antibodies
}

\author{
Yuan $\mathrm{Liu}^{1 \dagger}$, Xining $\mathrm{Liao}^{2 \dagger}$ and Guixiu Shi ${ }^{1 *}$ \\ ${ }^{1}$ Department of Rheumatology and Clinical Immunology, The First Affiliated Hospital of Xiamen University, Xiamen, China, \\ ${ }^{2}$ Medical College, Xiamen University, Xiamen, China
}

OPEN ACCESS

Edited by:

Francesco Ciccia,

University of Palermo, Italy

Reviewed by:

Yong-Gil Kim,

University of Ulsan College of

Medicine, South Korea

Shengjun Wang,

Jiangsu University, China

*Correspondence:

Guixiu Shi

guixiu.shi@gmail.com

${ }^{\dagger}$ These authors have contributed equally to this work

Specialty section: This article was submitted to Inflammation,

a section of the journal

Frontiers in Immunology

Received: 05 June 2018 Accepted: 02 January 2019

Published: 22 January 2019

Citation:

Liu Y, Liao X and Shi G (2019) Autoantibodies in Spondyloarthritis, Focusing on Anti-CD74 Antibodies. Front. Immunol. 10:5

doi: 10.3389/fimmu.2019.00005
Spondyloarthritis (SpA) is an inflammatory rheumatic disease with diverse clinical presentation. The diagnosis of SpA remains a big challenge in daily clinical practice because of the limitation in specific biomarkers of SpA, more biomarkers are still needed for SpA diagnosis and disease activity monitoring. In the past, SpA was considered predominantly as auto-inflammatory disease vs. autoimmune disease. However, in recent years several researches demonstrated a broad autoantibody response in SpA patients. Study also indicated that mice lack of ZAP70 in T cell develop SpA featured inflammation. These studies indicated the autoimmune features of SpA and gave rise to the potential use of autoantibody in SpA management. In this article, we reviewed recent reports of autoantibodies associated with SpA patients, revealing the autoimmune features of SpA, suggesting the hypothesis that SpA was also an autoimmune disease, studies about the autoimmune features might provide more insights in the pathogenesis of SpA. In addition, as there are two opposite conclusions in the role of anti-CD74 autoantibody in the diagnosis of SpA, we also gave our own data on the diagnostic value of anti-CD74 in Chinese SpA patients. Though our data indicated that anti-CD74 might not be a good biomarker for SpA diagnosis in Asian people, CD74 was still a good molecule target in the research of SpA pathogenesis.

Keywords: spondyloarthritis, autoantibodies, diagnosis, anti-CD74 autoantibody, Chinese patients

\section{INTRODUCTION}

Spondyloarthritis $(\mathrm{SpA})$ is an inflammatory rheumatic disease with diverse clinical presentation, including psoriatic arthritis, reactive arthritis, arthritis related to inflammatory bowel disease, a subgroup of juvenile idiopathic arthritis, and ankylosing spondylitis (AS) (1). The diagnosis of SpA remains a big challenge in daily clinical practice because of the limitation in specific biomarkers of SpA. Currently, HLA-B27 is the most widely used genetic biomarker in SpA diagnosis and CRP seems to be the best biomarker in evaluating disease activity of SpA (2). However, HLA-B27 can also be detected in healthy person and have no association with clinical presentation (3). Increased CRP lacks specificity in SpA because it can be detected in a large variety of inflammatory situations and it is found to be significant lower when new syndesmophytes development (4). Studies in recent years highly recommend the use of magnetic resonance imaging (MRI) in early diagnosis because its high sensitivity in detecting active sacroiliitis (5). However, MRI inflammatory abnormalities can also be detected in other diseases such as infection and it is costly in daily clinical practice for monitoring SpA. More biomarkers are still needed for SPA diagnosis and disease activity monitoring.

In the past, most immunologists believed the predominance of innate vs. adaptive immune responses in SpA, indicating a prominent autoinflammatory component in pathogenesis (6). Since 
SpA was considered as an inflammatory disease, autoantibodies were rarely used in diagnosis of SpA. However, several studies in recent years detected some autoantibodies in serum of SpA patients and also demonstrated a broad autoantibody response in these patients. Furthermore, as human immune response is a network, innate and adaptive immune responses promote and connect with each other and often accompanied by secondary $\mathrm{T}$ cell and B-cell activation, especially several studies indicated that Th17 cells might be involved in the pathogenesis of $\operatorname{SpA}(7,8)$. In addition, study also showed that mice lack of ZAP70 in T cell developed SpA featured inflammation (9). These studies revealed the autoimmune features of $\mathrm{SpA}$ and give rise to the hypothesis that $\mathrm{SpA}$ was also an autoimmune disease and the potential use of autoantibody in SpA management (10).

Presence of autoantibody is a key characteristic of autoimmune disease. Autoantibody is one of the most common biomarkers used in diagnosis and disease activity evaluating of autoimmune disease, it shows good sensitivity because it can sometimes be detected in serum years before the abnormal state of antigen been detected. In this article, we reviewed recent reports of autoantibodies associated with SpA patients to further reveal the autoimmune features of SpA and potential autoantigens. In addition, as there are two opposite conclusions in the role of anti-CD74 in the diagnosis of SpA, we also studied the presence of anti-CD74 in Chinese SpA patients.

\section{AUTOANTIBODIES IN SPA PATIENTS}

\section{Anti-beta2 Microglobulin Autoantibodies}

Beta 2 microglobulin, also known as B2M, it is the light chain of the human lymphocyte antigen (HLA) and a component of major histocompatibility complex (MHC) class I molecules on all nucleated cells $(11,12)$. In normal adults, there are small amounts of beta 2 microglobulin in serum, and ordinarily remained at a relatively stable level. However, in exceptional circumstances, the level of beta 2 microglobulin in serum would be change, like renal failure, after a trauma and tumor. Some investigators have found that the expression of beta 2 microglobulin elevated in some immune diseases, such as systemic lupus erythematosus (SLE) $(11,13)$, rheumatoid arthritis (RA) and Sjögren's syndrome (14-16), and anti-beta2 microglobulin was also detected in SLE patients (17-19). In order to explored the presence of anti-beta2 microglobulin in other common rheumatic diseases, Russell Curry et al. detected the expression of anti-beta2 microglobulin in AS, SLE, RA patients, and healthy controls. They showed that IgG antibody to beta 2 microglobulin was found in $68 \%$ of 22 patients with AS, although the presence of IgG anti-beta2 microglobulin was $71 \%$ in 35 SLE patients, the level of antibeta 2 microglobulin in AS patients was highest in all groups (20). Regrettably, we did not find any further investigations of this antibody in AS.

\section{Anti-mutated Citrullinated Vimentin Autoantibodies (Anti-MCV)}

Anti-citrullinated protein/peptide autoantibodies (ACPAs) are widely used in diagnosis of rheumatoid arthritis (RA), but their relationship with $\mathrm{SpA}$ is still unclear. Some recent studies used genetically modified, mutated citrullinated vimentin (MCV) as auto-antigen to detected antibodies to citrullinated vimentin (CV). One research indicated that the serum anti-MCV level was higher in patients with AS in comparison to healthy controls, and the prevalence of anti-MCV in AS patients was 37\% compared with $0 \%$ in healthy controls. In this study, there was no significant difference in the expression of this autoantibody in different types of spondylitis. Furthermore, anti-MCV positivity was correlated with erythrocyte sedimentation rate (ESR) in AS patients, but no correlation with age, disease duration, $C$ reactive protein (CRP), HLA-B27 status, smoking habits, pain intensity (VAS), Bath Ankylosing Spondylitis Disease Activity Index (BASDAI), Bath Ankylosing Spondylitis Functional Index (BASFI) or Bath Ankylosing Spondylitis Metroloty Index (BASMI)(21). Another research compared the diagnostic value of anti-MCV in differentiating early inflammatory arthritis, they found $13.9 \%$ patients in AS can be detected anti-MCV in their serum, while $15.2 \%$ in psoriatic arthritis and $62 \%$ in rheumatoid arthritis patients (22).

\section{Anti-heat Shock Protein 65 Autoantibodies (Anti-HSP65)}

Heat shock proteins (HSPs) are highly conserved proteins with protective functions in situations of cellular stress. HSP65 was one of HSPs named according to its molecular weight. Autoantibodies to HSPs had been found in several kinds of diseases including cancer and inflammatory disease. Recently, higher level of anti-HSP65 in patients with AS than in healthy controls was shown in a research, but the number of patients included in this study was relatively small, they only compared 43 AS patients with 11 patients with low back pain but no AS (21). On the contrary, another study indicated that although antihsp65 was elevated in 19/59 patients (32\%), the level of elevation was not significant. At the same time, they also detected the expression of anti-hsp65 in RA, in contrast, significantly elevated IgA anti-HSP65 was observed in RA (23).

\section{Anti-14-3-3 eta

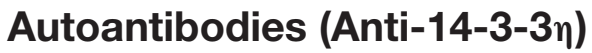

Traditionally, $14-3-3 \eta$ (eta) is regarded as an intracellular protein. Like other intracellular protein, such as HSPs, upon

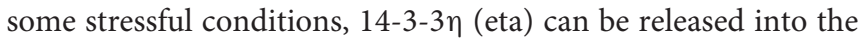
extracellular compartments, and elicits a specific auto-antibody

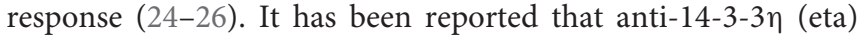
has specificity and sensitivity in patients with early RA and that it may be used for the diagnosis of early RA, at the same

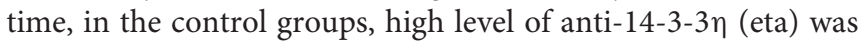
observed in patients with AS (27). Subsequently, Maksymowych

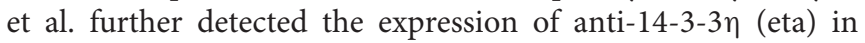
patients with AS and assessed the relationship between anti-14$3-3 \eta$ (eta) and sacroiliac joints (SIJ) inflammation. They found

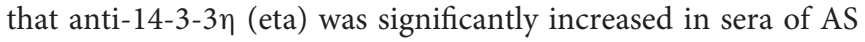
patients and correlated with SIJ inflammation, C-reactive protein (CRP), baseline modified stoke ankylosing spondylitis spine score (mSASSS), and change in mSASSS in AS patients (28). 


\section{Anti-protein Phosphatase Magnesium-Dependent 1A Autoantibodies (Anti-PPM1A)}

Differentiation of osteoblasts leads to syndesmophytes formation is a key feature of $\mathrm{AS}$, this process requires the participation of some signaling pathways, such as bone morphogenetic proteins (BMPs), Wingless proteins (Wnt), and so on (29). Protein Phosphatase Magnesium-Dependent 1A (PPM1A) is a serine/threonine (Ser/Thr) protein phosphatase known as an inhibitor of tumor growth factor (TGF)- $\beta$ signaling pathway, participates in bone formation by regulating BMP and Wnt signaling pathway $(30,31)$. High-density protein microarrays showed that higher auto-reactivity against PPM1A was detected in AS patients than in other autoimmune diseases. Then, in Korean patients, compared with RA patients $(n=20)$ and healthy controls $(n=30)$, significantly higher levels of anti-PPM1A were observed in treatment-naïve patients with AS $(n=45)$. Furthermore, AS patients with grade 3 or 4 radiographic sacroiliitis, the levels of anti-PPM1A were also higher than in those with grade 2 radiographic sacroiliitis. After treatment with a TNF inhibitor, the serum levels of anti-PPM1A were significantly decreased in patients with AS, and correlated positively with BASDAI score. These results indicated that anti-PPM1A autoantibodies might not only serve as a diagnostic biomarker, but also associated with severity of sacroiliitis, and might be used as a predictor of response to anti-TNF therapy in AS patients. In addition, they also found that the expression of PPM1A was increased in AS patients, indicated that PPM1A might also be involved in pathogenesis of AS (31).

\section{Anti-sclerostin Autoantibodies (Anti-SOST)}

As mentioned earlier, bone formation plays an important role in the pathogenesis of AS (32), and as the expression product of the sclerostin gene (SOST), sclerostin is an inhibitor of bone formation and plays a crucial role in the formation of bone (33). One study had shown that in the comparison of AS, RA, osteoarthritis (OA) and healthy controls, lower sclerostin level was observed in OA and AS patients, especially in AS patients (34). Meanwhile, another study had indicated that the overexpression of anti-SOST would lead to lower level of SOST (35). Based on these research results, Michele Maria Luchetti et al. further studied the significance of anti-SOST-IgG in the diagnosis of SpA, they focused their attention on spondyloarthritisassociated inflammatory bowel diseases (SpA/IBD), one of the group of SpA. They found that the level of anti-SOST-IgG was significantly higher in axial spondyloarthritis-associated inflammatory bowel diseases (axSpA/IBD) patients compared with peripheral SpA/IBD (per-SpA/IBD) and IBD patients (43.29 $\pm 13.74,21.33 \pm 11.33,27.27 \pm 11.77 \mathrm{IU} / \mathrm{ml}$, respectively), and they also found anti-SOST-IgG serum levels were inversely associated with the duration of articular symptoms (36). They indicated that anti-SOST-IgG might be used as a potential biomarker in axial SpA in patients with IBD, in addition, the presence of anti-SOST-IgG and reduction of SOST might be used as a new target in the study of SPA pathogenesis.

\section{Antibodies Against Microbial Targets}

Several antibodies against microbial targets have been detected in serum of inflammatory bowel disease (IBD) patients, suggesting loss of tolerance to a subset of commensal microorganisms (37). These include anti-Saccharomyces cerevesiae antibodies (ASCA) directed against a cell wall polysaccharide of the yeast, anti-neutrophil cytoplasmic antibodies (pANCA), antiI2 (associated with anti-Pseudomonas activity), anti-Eschericia coli outer membrane porin C (anti-OmpC), and anti-flagellin (anti-CBir1). As AS patients share many similarities with IBD patients, those antibodies have also been detected in serum of AS patients. Increased prevalence of ASCA, ANCA, and anti-CBir1 were found in AS patients by some studies (3840), while other studies showed no significant difference in positivity rates of those antibodies in AS patients $(41,42)$. Clinical significance of those antibodies in SPA patients still needed to be evaluated.

\section{Anti-CD74 Autoantibodies}

\section{Anti-CD74 Autoantibody in European SpA Patients}

The human CD74, also known as human lymphocyte antigen (HLA) class II gamma chain or invariant chain, is considered as part of formation and transport of major histocompatibility complex class II (MHC II) molecules (43). There are two different domains in the extracellular part of CD74, class II-associated invariant chain peptide (CLIP) was one of them. The main function of CLIP is to prevent the binding of premature peptide to newly assembled class II HLA molecules (44-46). Some researchers have found that the interaction between anti-CLIP antibodies and CD74 may produce proinflammatory cytokines, such as tumor necrosis factor $\alpha$ (TNF $\alpha)$ (47). Recently, some German researchers screened new autoantigens by using protein array technology based on cDNA of fetal brain tissue. A total of 59 sera were studied, including different inflammatory and rheumatic diseases $(n=55,5$ radiographic axial SpA) and 4 healthy controls. IgG antibodies against CD74 were detected in 4/5 radiographic axial SpA patients, while in 54 controls, only 1 of them was detected IgG antibodies against CD74. Since there has been little research on the role of another extracellular part of CD74, thyroglobulin type-1 in CD74, the researchers focused their attention on CLIP. So, they detected the serum level of anti-CD74 and anti-CLIP in patients by ELISA, the results showed anti-CD74 IgG protein in 23/41 (56\%) patients with radiographic axial SpA, compared with $5 / 100$ (5\%) in blood donors, meanwhile, anti-CLIP IgG was found to present in sera of $67 \%$ SpA patients and was even more frequent in patients with a short duration, but had no association with disease activity, indicating it might be used as a biomarker in the early diagnosis of SpA. This study included $216 \mathrm{SpA}$ patients from Hannover, Berlin and Vienna (48). Another European study also came to similar results (49). These studies provided preliminary evidence that anti-CD74 antibody might be a promising biomarker in SpA diagnosis.

However, a study indicated that anti-CD74 IgG and IgA autoantibodies have no diagnostic value in early axial spondyloarthritis (50). In this study, compared with patients 
with chronic back pain (CBP), the level of serum anti-CD74 IgG autoantibody did not elevate in early axSpA patients, and the difference in prevalence of anti-CD74 IgG autoantibody in axSpA and CBP patients was not significant (46.4, 47.9\%, respectively). On the other hand, although level of anti-CD74 $\operatorname{IgA}$ was higher in patients with early axSpA, this elevation was not sufficiently specific to yield significant diagnostic value in patients under 45 years old presenting with early back pain.

\section{The Presence of Anti-CD74 Autoantibody in Chinese SpA Patients}

As the role of anti-CD74 in the diagnosis of SpA is still controversial, we further investigated presence of anti-CD74 in sera of Chinese SpA patients by ELISA. A total of 141 sera obtained from the serum bank of the First Affiliated Hospital of Xiamen University, including 71 patients with SpA and 70 healthy controls (HC). All the sera had been stored for less than 1 year at $-80^{\circ} \mathrm{C}$ before they were studied. All patients were diagnosed by the rheumatologist, and fulfilled the modified New York (mNY) criteria for AS. The medical ethic committee of The First Affiliated Hospital of Xiamen University has approved this study. We found that although the mean titer of anti-CD74 in SpA patients was higher than healthy controls, the prevalence of anti-CD74 was not as high as the results from the Europe cohort (Figure 1A). We also used the receiver operating characteristic curves (ROC) to demonstrate the sensitivity and specificity of anti-CD74 in diagnosis of SpA (Figure 1B). The ROC curve revealed not very strong performance characteristics of antiCD74 in Chinese SpA patients, with AUC values of 0.608 , and $95 \%$ confidence intervals of $0.513-0.704$. By using the mean titer of HC plus two SDs as the cut-off value to determine the sera samples with positive anti-CD74, the prevalence of antiCD74 in Chinese SpA patients was $14.1 \%$, and $2.9 \%$ in healthy controls (Table 1). We also analyzed the correlation of titer of anti-CD74 and Ankylosing Spondylitis Disease Activity ScoreC Reactive Protein (ASDAS-CRP), Bath Ankylosing Spondylitis
Disease Activity Index (BASDAI), patient global assessment, swelling/pain peripheral joint, morning stiffness, fatigue, levels of back pain, erythrocyte sedimentation rate (ESR) and C reactive protein (CRP). As shown in Figure 2, no significant correlation was found between titer of anti-CD74 and these disease activity indexes, except swelling/pain peripheral joint, morning stiffness (Figure 2).

We used Graphpad prism 7.0 for statistical analysis. Comparisons between groups were evaluated using the MannWhitney $U$ test. For correlations we used the Spearman test. Statistical analysis was performed in SPSS 20.0 software, and $P<0.05$ was considered statistically significant.

\section{Possible Reasons for Difference in Diagnostic Value of Anti-CD74 Among Studies and Possible Role of CD74 on the Pathogenesis of SpA}

Our study showed prevalence of anti-CD74 was not as high as the results from the Europe cohort. This might result from difference in study population, indicating that anti-CD74 might not be a good biomarker for SpA diagnosis in Chinese patients. Also, as discussed in the study of anti-CD74, soluble CD74 was presented in fresh sera that may interfere the binding of autoantibody to CD74 with CD74 on ELISA plate, the sera used in the study of anti-CD74 were frozen for years, in which soluble CD74 appeared to be slowly degraded after years (48). The sera in our study were kept froze less than 1 year, this might be one of the factors contribute to low prevalence of anti-CD74 in our study.

TABLE 1 | Frequency of autoantibody against CD74 in human sera by ELISA.

\begin{tabular}{cccc}
\hline & Number & Anti-CD74 (+) & Frequency (\%) \\
\hline HC & 70 & 2 & 2.9 \\
SPA & 71 & 10 & $14.1^{*}$ \\
\hline
\end{tabular}

HC, healthy control; SPA, spondyloarthritis. ${ }^{*} P<0.05$.

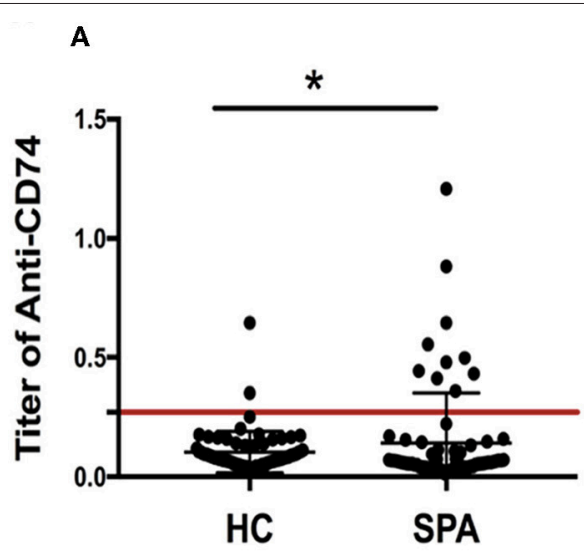

B

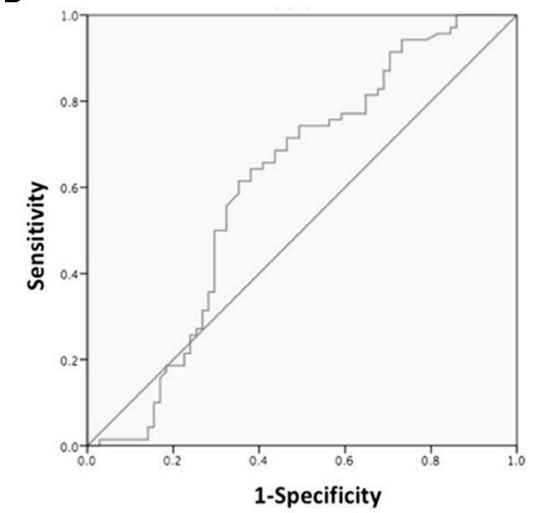

FIGURE 1 | (A) Titer of anti-CD74 autoantibody by ELISA. Titer of anti-CD74 in SpA serum was higher than that in healthy controls, but the prevalence of anti-CD74 was not as high as the results from the Europe cohort. The cutoff value line for positive samples is indicated in the figure. (B) Receiver operating characteristic curves (shown as area under the curve [AUC]) demonstrated the sensitivity and specificity of anti-CD74 Ab in diagnosis of SpA. AUC = 0.608, with 95\% confidence intervals of $0.513-0.704$. ${ }^{*} p<0.05$. 

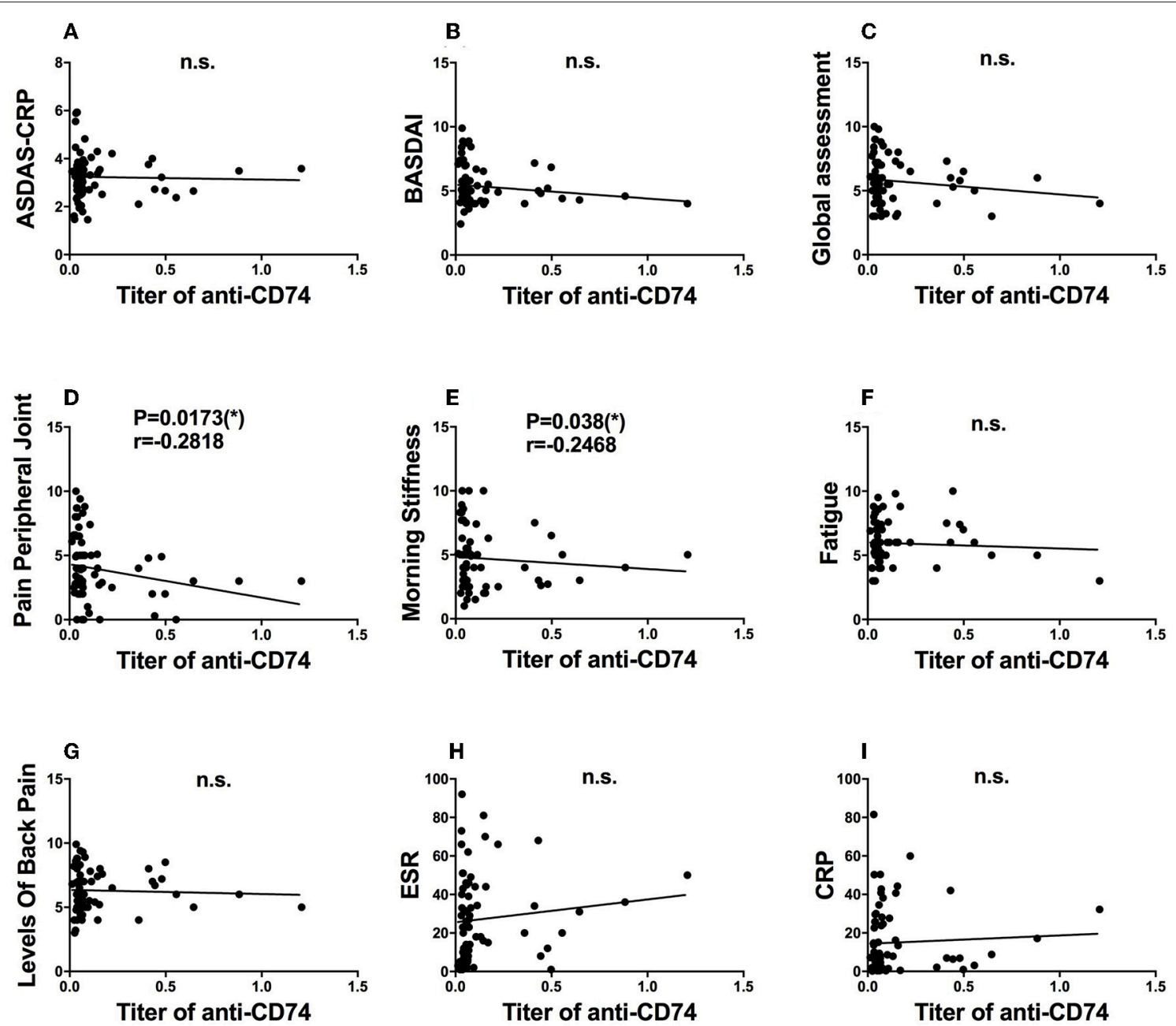

FIGURE 2 | Clinical significance of anit-CD74 autoantibody in SpA patients. Association of titer of anit-CD74 and ASDAS-CRP (A); BASDAI (B); patient global assessment (C); pain peripheral joint (D); morning stiffness (E); fatigue (F); levels of back pain (G); erythrocyte sedimentation rate (ESR) (H) and C reactive protein (CRP) (I) were determined by using spearman's correlation test, no significant correlation was found between titer of anti-CD74 and these disease activity index, except pain peripheral joint morning stiffness.

CD74 has been proved to be one of the key regulators in inflammation by many studies. It is expressed on several types of immune cells such as dendritic cells, macrophages and $\mathrm{B}$ cells, performed activities in antigen presentation, B cell differentiation, motility of dendritic cells and thymic selection (51), which are all important in pathogenesis of inflammation. Activation of CD74 initiates signaling cascade which leading to NF- $\mathrm{KB}$ activation (52), which are important in production of proinflammatory cytokines. Many studies have demonstrated role of $\mathrm{CD} 74$ in several kinds of inflammatory or autoimmune diseases such as atherosclerosis, lupus, and diabetes mellitus (51). It can be speculated that CD74 might be involved in pathogenesis of SpA from role of CD74 in inflammation. Autoantibodies to CD74 might be involved in pathogenesis of SpA by activating CD74 and leading to production of proinflammatory cytokines. Though our studies showed that anti-CD74 might not be a good diagnostic biomarker for SpA patients in Asian, CD74 is still a good molecule to be studied in SpA pathogenesis mechanism and treatment.

\section{CONCLUSION}

SpA was long considered as an autoinflammatory disease and researches about biomarkers of SpA mainly focused on innate immunity components. As presence of autoantibodies in serum of SpA patients was found by studies, the hypothesis that $\mathrm{SpA}$ was also an autoimmune disease has been proved gradually, the involvements of adaptive immune system in the pathogenesis will attract more attention to rheumatologists as well as clinical immunologists. In the future, autoantibodies in $\mathrm{SpA}$ patients need to be detected in different populations and large number of SpA patients. As the involvements of adaptive immune system in the pathogenesis being revealed, autoantibodies and cellular immune components may become important 
biomarker as well as new therapeutic targets, which may greatly improve the diagnosis and management of SpA patients.

\section{AUTHOR CONTRIBUTIONS}

All the authors were involved in the design of the study and in writing the manuscript. YL and XL participated in the study design, literature review, collected serum samples, and performed statistical analysis and presentation of the results and participated in the drafting and review of the manuscript. GS participated in the study design, and participated in the drafting and review of the manuscript.

\section{REFERENCES}

1. Dougados M, Baeten D. Spondyloarthritis. Lancet (2011) 377:2127-37. doi: 10.1016/S0140-6736(11)60071-8

2. Prajzlerova K, Grobelna K, Pavelka K, Senolt L, Filkova M. An update on biomarkers in axial spondyloarthritis. Autoimmun Rev. (2016) 15:501-9. doi: 10.1016/j.autrev.2016.02.002

3. van der Linden SM, Valkenburg HA, de Jongh BM, Cats A. The risk of developing ankylosing spondylitis in HLA-B27 positive individuals. A comparison of relatives of spondylitis patients with the general population. Arthritis Rheumat. (1984) 27:241-9. doi: 10.1002/art.17802 70301

4. Pedersen SJ, Sorensen IJ, Lambert RG, Hermann KG, Garnero P, Johansen JS, et al. Radiographic progression is associated with resolution of systemic inflammation in patients with axial spondylarthritis treated with tumor necrosis factor alpha inhibitors: a study of radiographic progression, inflammation on magnetic resonance imaging, and circulating biomarkers of inflammation, angiogenesis, and cartilage and bone turnover. Arthritis Rheumat. (2011) 63:3789-800. doi: 10.1002/art. 30627

5. Rudwaleit M, Jurik AG, Hermann KG, Landewe R, van der Heijde D, Baraliakos X, et al. Defining active sacroiliitis on magnetic resonance imaging (MRI) for classification of axial spondyloarthritis: a consensual approach by the ASAS/OMERACT MRI group. Annals Rheumat Dis. (2009) 68:1520-7. doi: 10.1136/ard.2009.110767

6. Ambarus C, Yeremenko N, Tak PP, Baeten D. Pathogenesis of spondyloarthritis: autoimmune or autoinflammatory? Curr Opin Rheumatol. (2012) 24:351-8. doi: 10.1097/BOR.0b013e3283534df4

7. Taams LS, Steel KJA, Srenathan U, Burns LA, Kirkham BW. IL-17 in the immunopathogenesis of spondyloarthritis. Nat Rev Rheumatol. (2018) 14:453-66. doi: 10.1038/s41584-018-0044-2

8. Raychaudhuri SP, Raychaudhuri SK. IL-23/IL-17 axis in spondyloarthritis-bench to bedside. Clin Rheumatol. (2016) 35:1437-41. doi: 10.1007/s10067-016-3263-4

9. Ruutu M, Thomas G, Steck R, Degli-Esposti MA, Zinkernagel MS, Alexander $\mathrm{K}$, et al. beta-glucan triggers spondylarthritis and Crohn's disease-like ileitis in SKG mice. Arthritis Rheumat. (2012) 64:2211-22. doi: 10.1002/art. 34423

10. Wright C, Sibani S, Trudgian D, Fischer R, Kessler B, LaBaer J, et al. Detection of multiple autoantibodies in patients with ankylosing spondylitis using nucleic acid programmable protein arrays. Mol Cell Proteomics (2012) 11:M9.00384. doi: 10.1074/mcp.M9.00384

11. Vitetta ES, Poulik MD, Klein J, Uhr JW. Beta 2-microglobulin is selectively associated with H-2 and TL alloantigens on murine lymphoid cells. J Exp Med. (1976) 144:179-92. doi: 10.1084/jem.144.1.179

12. Gussow D, Rein R, Ginjaar I, Hochstenbach F, Seemann G, Kottman A, et al. The human beta 2-microglobulin gene. Primary structure and definition of the transcriptional unit. J Immunol. (1987) 139:3132-8.

\section{FUNDING}

The work was supported by National Key Basic Research Program of China (973 Program, No. 2014CB541903) to GS; NSFC (Natural Science Foundation of China) grant 81501407 to YL; NSFC grant 81501369 to Dr. Shiju Chen NSFC grant 8160060958 to Dr. Hongyan Qian.

\section{ACKNOWLEDGMENTS}

We are extremely grateful to all the patients and volunteers who took part in this study, as well as the whole rheumatology team, including nurses, medical record system personnel, and laboratory technicians.

13. Weissel M, Scherak O, Fritzsche H, Kolarz G. Letter: serum beta2-microglobulin and SLE. Arthritis Rheumat. (1976) 19:968. doi: 10.1002/art.1780190532

14. Talal N, Grey HM, Zvaifler N, Michalski JP, Daniels TE. Elevated salivary and synovial fluid beta2-microglobulin in Sjogren's syndrome and rheumatoid arthritis. Science (1975) 187:1196-8. doi: 10.1126/science.46621

15. Manicourt D, Brauman H, Orloff S. Plasma and urinary levels of beta2 microglobulin in rheumatoid arthritis. Ann Rheumat Dis. (1978) 37:328-32. doi: 10.1136/ard.37.4.328

16. Strom T, Evrin PE, Karlsson A. Serum beta-2-microglobulin in Sjogren's syndrome. Scandinav J Rheumatol. (1978) 7:97-100. doi: 10.3109/03009747809098844

17. Ooi BS, Ooi YM, Pesce AJ, Pollak VE. Antibodies to beta 2 microglobulin in the sera of patients with systemic lupus erythematosus. Immunology (1977) 33:535-41.

18. Revillard JP, Vincent C, Rivera S. Anti-beta2-microglobulin lymphocytotoxic autoantibodies in systemic lupus erythematosus. J Immunol. (1979) 122:614-8.

19. Messner RP, De Horatius R, Ferrone S. Lymphocytotoxic antibodies in systemic lupus erythematosus patients and their relatives: reactivity with the HLA antigenic molecular complex. Arthritis Rheumatism (1980) 23:265-72. doi: 10.1002/art.1780230301

20. Curry R, Thoen J, Shelborne C, Gaudernack G, Messner R. Antibodies to and elevations of beta 2 microglobulin in the serum of ankylosing spondylitis patients. Arthritis Rheumat. (1982) 25:375-80. doi: 10.1002/art.1780250403

21. Bodnar N, Szekanecz Z, Prohaszka Z, Kemeny-Beke A, Nemethne-Gyurcsik Z, Gulyas K, et al. Anti-mutated citrullinated vimentin (anti-MCV) and anti-65 kDa heat shock protein (anti-hsp65): new biomarkers in ankylosing spondylitis. Joint Bone Spine (2012) 79:63-6. doi: 10.1016/j.jbspin.2011.03.010

22. Damjanovska L, Thabet MM, Levarth EW, Stoeken-Rijsbergen G, van der Voort EI, Toes RE, et al. Diagnostic value of anti-MCV antibodies in differentiating early inflammatory arthritis. Ann Rheumat Dis. (2010) 69:7302. doi: 10.1136/ard.2009.108456

23. McLean IL, Archer JR, Cawley MI, Pegley FS, Kidd BL, Thompson PW Specific antibody response to the mycobacterial $65 \mathrm{kDa}$ stress protein in ankylosing spondylitis and rheumatoid arthritis. Br J Rheumatol. (1990) 29:426-9. doi: 10.1093/rheumatology/29.6.426

24. Clayton A, Turkes A, Navabi H, Mason MD, Tabi Z. Induction of heat shock proteins in B-cell exosomes. J Cell Sci. (2005) 118:3631-8. doi: $10.1242 /$ jcs. 02494

25. Lancaster GI, Febbraio MA. Exosome-dependent trafficking of HSP70: a novel secretory pathway for cellular stress proteins. J Biol Chem. (2005) 280:23349-55. doi: 10.1074/jbc.M502017200

26. Chavez-Munoz C, Kilani RT, Ghahary A. Profile of exosomes related proteins released by differentiated and undifferentiated human keratinocytes. J Cell Physiol. (2009) 221:221-31. doi: 10.1002/jcp.21847

27. Maksymowych WP, Naides SJ, Bykerk V, Siminovitch KA, van Schaardenburg D, Boers M, et al. Serum 14-3-3eta is a novel marker that complements current 
serological measurements to enhance detection of patients with rheumatoid arthritis. J Rheumatol. (2014) 41:2104-13. doi: 10.3899/jrheum.131446

28. Kalyoncu U, Karadag O, Kilic L, Ertenli I, Bilgen SA, Akdogan A, et al. THU0104 risk factors of advanced spinal disease and/or bamboo disease in patients with ankylosing sponylitis during TNFI treatments: HÜR-BIO real life results. Ann Rheumat Dis. (2014) 73:213. doi: 10.1136/annrheumdis-2014-eular.4041

29. Schett $\mathrm{G}$. Bone formation versus bone resorption in ankylosing spondylitis. Adv Exp Med Biol. (2009) 649:114-21. doi: 10.1007/978-1-4419-0298-6_8

30. Zolnierowicz S. Type $2 \mathrm{~A}$ protein phosphatase, the complex regulator of numerous signaling pathways. Biochem Pharmacol. (2000) 60:1225-35. doi: 10.1016/S0006-2952(00)00424-X

31. Kim YG, Sohn DH, Zhao X, Sokolove J, Lindstrom TM, Yoo B, et al. Role of protein phosphatase magnesium-dependent $1 \mathrm{~A}$ and anti-protein phosphatase magnesium-dependent 1A autoantibodies in ankylosing spondylitis. Arthritis Rheumatol. (2014) 66:2793-803. doi: 10.1002/art.38763

32. Sieper J, Appel H, Braun J, Rudwaleit M. Critical appraisal of assessment of structural damage in ankylosing spondylitis: implications for treatment outcomes. Arthritis Rheumat. (2008) 58:649-56. doi: 10.1002/art. 23260

33. Poole KE, van Bezooijen RL, Loveridge N, Hamersma H, Papapoulos SE, Lowik CW, et al. Sclerostin is a delayed secreted product of osteocytes that inhibits bone formation. FASEB J. (2005) 19:1842-4. doi: 10.1096/fj.05-4221fje

34. Appel H, Ruiz-Heiland G, Listing J, Zwerina J, Herrmann M, Mueller R, et al. Altered skeletal expression of sclerostin and its link to radiographic progression in ankylosing spondylitis. Arthritis Rheumat. (2009) 60:3257-62. doi: $10.1002 /$ art.24888

35. Tsui FW, Tsui HW, Las Heras F, Pritzker KP, Inman RD. Serum levels of novel noggin and sclerostin-immune complexes are elevated in ankylosing spondylitis. Annals Rheumat Dis. (2014) 73:1873-9. doi: 10.1136/annrheumdis-2013-203630

36. Luchetti MM, Ciccia F, Avellini C, Benfaremo D, Guggino G, Farinelli A, et al. Sclerostin and antisclerostin antibody serum levels predict the presence of axial spondyloarthritis in patients with inflammatory bowel disease. $J$ Rheumatol. (2018) 45:630-7. doi: 10.3899/jrheum.170833

37. Landers CJ, Cohavy O, Misra R, Yang H, Lin YC, Braun J, et al. Selected loss of tolerance evidenced by Crohn's disease-associated immune responses to auto- and microbial antigens. Gastroenterology (2002) 123:68999. doi: 10.1053/gast.2002.35379

38. Wallis D, Asaduzzaman A, Weisman M, Haroon N, Anton A, McGovern D, et al. Elevated serum anti-flagellin antibodies implicate subclinical bowel inflammation in ankylosing spondylitis: an observational study. Arthritis Res Ther. (2013) 15:R166. doi: 10.1186/ar4350

39. Aydin SZ, Atagunduz P, Temel M, Bicakcigil M, Tasan D, Direskeneli H. Anti-Saccharomyces cerevisiae antibodies (ASCA) in spondyloarthropathies: a reassessment. Rheumatology (2008) 47:142-4. doi: 10.1093/rheumatology/kem324

40. Torok HP, Glas J, Gruber R, Brumberger V, Strasser C, Kellner H, et al. Inflammatory bowel disease-specific autoantibodies in HLA-B27-associated spondyloarthropathies: increased prevalence of ASCA and pANCA. Digestion (2004) 70:49-54. doi: 10.1159/000080081
41. Riente L, Chimenti D, Pratesi F, Delle Sedie A, Tommasi S, Tommasi C, et al. Antibodies to tissue transglutaminase and Saccharomyces cerevisiae in ankylosing spondylitis and psoriatic arthritis. J Rheumatol. (2004) 31:920-4. Available online at: http://www.jrheum.org/content/31/5/920.tab-article-info

42. Mundwiler ML, Mei L, Landers CJ, Reveille JD, Targan S, Weisman MH. Inflammatory bowel disease serologies in ankylosing spondylitis patients: a pilot study. Arthritis Res Ther. (2009) 11:R177. doi: 10.1186/ar2866

43. Cresswell P. Assembly, transport, and function of MHC class II molecules. Annu Rev Immunol. (1994) 12:259-93. doi: 10.1146/annurev.iy.12.040194.001355

44. Lotteau V, Teyton L, Peleraux A, Nilsson T, Karlsson L, Schmid SL, et al. Intracellular transport of class II MHC molecules directed by invariant chain. Nature (1990) 348:600-5. doi: 10.1038/348600a0

45. Matza D, Wolstein O, Dikstein R, Shachar I. Invariant chain induces B cell maturation by activating a TAF(II)105-NF-kappaB-dependent transcription program. J Biol Chem. (2001) 276:27203-6. doi: 10.1074/jbc.M104684200

46. Arneson LS, Miller J. The chondroitin sulfate form of invariant chain trimerizes with conventional invariant chain and these complexes are rapidly transported from the trans-Golgi network to the cell surface. Biochem J. (2007) 406:97-103. doi: 10.1042/BJ20070446

47. Starlets D, Gore Y, Binsky I, Haran M, Harpaz N, Shvidel L, et al. Cell-surface CD74 initiates a signaling cascade leading to cell proliferation and survival. Blood (2006) 107:4807-16. doi: 10.1182/blood-2005-11-4334

48. Baerlecken NT, Nothdorft S, Stummvoll GH, Sieper J, Rudwaleit M, Reuter S, et al. Autoantibodies against CD74 in spondyloarthritis. Ann Rheumat Dis. (2014) 73:1211-4. doi: 10.1136/annrheumdis-2012-202208

49. Baraliakos X, Baerlecken N, Witte T, Heldmann F, Braun J. High prevalence of anti-CD74 antibodies specific for the HLA class II-associated invariant chain peptide (CLIP) in patients with axial spondyloarthritis. Ann Rheum Dis. (2014) 73:1079-82. doi: 10.1136/annrheumdis-2012-202177

50. de Winter JJ, van de Sande MG, Baerlecken N, Berg I, Ramonda R, van der Heijde D, et al. Anti-CD74 antibodies have no diagnostic value in early axial spondyloarthritis: data from the spondyloarthritis caught early (SPACE) cohort. Arthritis Res Ther. (2018) 20:38. doi: 10.1186/s13075-018-1535-x

51. Borghese F, Clanchy FI. CD74: an emerging opportunity as a therapeutic target in cancer and autoimmune disease. Expert Opin Ther Targets (2011) 15:237-51. doi: 10.1517/14728222.2011.550879

52. Gil-Yarom N, Radomir L, Sever L, Kramer MP, Lewinsky H, Bornstein C, et al. CD74 is a novel transcription regulator. Proc Natl Acad Sci USA. (2017) 114:562-7. doi: 10.1073/pnas.1612195114

Conflict of Interest Statement: The authors declare that the research was conducted in the absence of any commercial or financial relationships that could be construed as a potential conflict of interest.

Copyright (c) 2019 Liu, Liao and Shi. This is an open-access article distributed under the terms of the Creative Commons Attribution License (CC BY). The use, distribution or reproduction in other forums is permitted, provided the original author(s) and the copyright owner(s) are credited and that the original publication in this journal is cited, in accordance with accepted academic practice. No use, distribution or reproduction is permitted which does not comply with these terms. 